\title{
Intravascular haemolysis and acute renal failure following potassium dichromate poisoning
}

\author{
B. K. Sharma \\ M.D., M.A.M.S.
P. C. Singhal
M.D., D.M. \\ K. S. Chugh \\ M.D., M.A.M.S., F.I.C.A.

\begin{abstract}
Divisions of Internal Medicine and Nephrology, Postgraduate Institute of Medical Education and Research, Chandigarh, India
\end{abstract}

\begin{abstract}
Summary
An 18-year-old girl developed acute renal failure $24 \mathrm{hr}$ after ingestion of potassium dichromate. Laboratory data revealed associated intravascular haemolysis. Renal histology showed features suggestive of acute tubular necrosis. She went into diuretic phase after 11 days of oliguria and subsequently regained normal renal function. Both direct toxic damage by dichromate and intravascular haemolysis may have contributed to the development of acute tubular necrosis and acute renal failure.
\end{abstract}

\section{Introduction}

Chronic chromate poisoning is a well known industrial hazard (Walsh, 1953), but acute poisoning because of potassium dichromate ingestion is rare (Kaufman, DiNicola and McIntosh, 1970). Fristedt et al. (1965) described a case of chromic acid poisoning with acute renal failure from which the patient recovered. A patient is now reported who developed acute renal failure following potassium dichromate ingestion and who recovered completely following dialysis. An additional point of interest in this case was intravascular haemolysis, a finding not well recognized in association with chromate poisoning.

Because of a bet with her classmate, an 18-year-old pre-medical student ingested a few grams of potassium dichromate. There followed nausea and repeated vomiting and, $3 \mathrm{hr}$ later, loose motions. Five hours after the ingestion, gastric lavage was carried out in a local hospital and the aspirate confirmed the presence of potassium dichromate. She received intravenous fluid and furosemide. Investigations revealed haemoglobin of $14 \mathrm{~g} / \mathrm{dl}$ and proteinuria $(+)$ and a few granular casts in the urine. In the next $24 \mathrm{hr}$ the patient passed $200 \mathrm{ml}$ of urine and developed jaundice. Examination revealed that the liver was mildly tender, and palpable $2 \mathrm{~cm}$ below the right costal margin. Blood urea nitrogen was $14.23 \mathrm{mmol} / \mathrm{l}$; serum creatinine $265 \mu \mathrm{mol} / \mathrm{l}$ and serum bilirubin was $51 \cdot 3 \mu \mathrm{mol} / 1$ (conjugated $17 \cdot 1 \mu \mathrm{mol} / \mathrm{l}$ ).

Reprint requests: Dr B. K. Sharma, Associate Professor of Medicine, Postgraduate Institute of Medical Education and Research, Chandigarh 160011, India.
As the oliguria continued beyond 4 days, she was referred to the Postgraduate Institute of Medical Education and Research, Chandigarh, for further management.

Examination at that time revealed moderate pallor, a pulse rate of $110 / \mathrm{min}$ and $\mathrm{BP}$ was $120 / 70 \mathrm{mmHg}$. She was jaundiced and had mild tenderness in the epigastric region. The cardiovascular and respiratory systems were normal. Laboratory investigations revealed: haemoglobin $7 \mathrm{~g} / \mathrm{dl}$; haematocrit $20 \%$, total leucocyte count $23 \times 10^{9} / 1$, reticulocyte count $11 \%$; plasma haemoglobin $0.35 \mathrm{~g} / 1$; serum sodium $128 \mathrm{mmol} / \mathrm{l}$; potassium $5.1 \mathrm{mmol} / \mathrm{l}$; chloride 880 $\mathrm{mmol} / \mathrm{l}$; bicarbonate $19 \mathrm{mmol} / \mathrm{l}$; bilirubin 60 $\mu \mathrm{mol} / 1$; SGOT 17 i.u.; SGPT 20 i.u.; alkalineo phosphatase $5.6 \mathrm{KAu}$; blood urea nitrogen 45.4 $\mathrm{mmol} / \mathrm{l}$; and serum creatinine $795 \mu \mathrm{mol} / \mathrm{l}$. The oliguria continued, so, on the 8th day after ingestion of the potassium dichromate, the patient was dialysed. Four days later (12th day), the patient passed $800 \mathrm{ml}$ of urine and very quickly passed on to the diuretic phase with a urine output of 2-4 litres (Fig. 1). A percutaneous renal biopsy performed

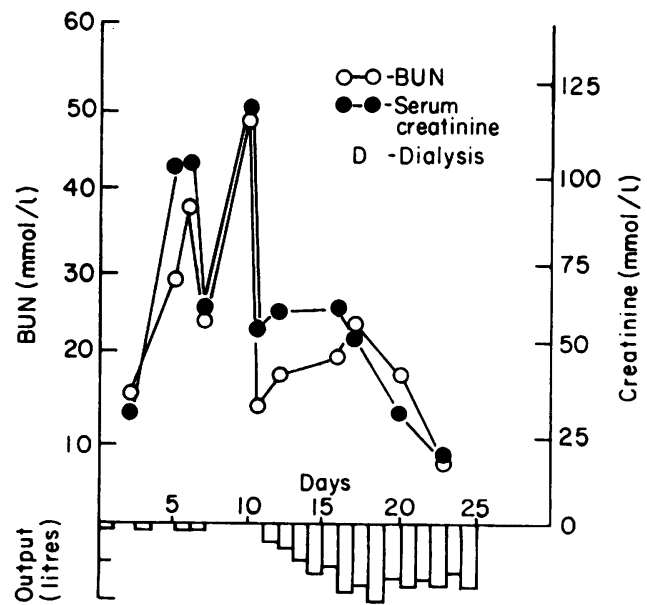

FIG. 1. Daily urine volume, blood urea nitrogen (BUN) and serum creatinine. 
on the 18th day showed a loss of tubular epithelial lining, interstitial oedema and evidence of regeneration, all indicating a picture of acute tubular necrosis. A liver biopsy was performed and showed no abnormality. The patient made a complete recovery and follow-up has shown no residual renal or hepatic abnormality.

\section{Discussion}

The clinical course of a patient after potassium dichromate intoxication is often complex. The immediate symptoms are generally in the form of nausea, vomiting and diarrhoea. These may be followed by hepatic failure (Goldman and Karotkin, 1935; Pascalle et al., 1952), renal failure (Fritz, Bohm and Lowen, 1960; Moeschlin, 1965; Sandar and Camp, 1939; Goldman and Karotkin, 1935; Samitz, 1964; Fristedt et al., 1965), thrombocytopenia and bleeding diathesis (Fritz et al., 1960; Fristedt et al., 1965). The central nervous system may be involved directly (Fritz et al., 1960) or secondarily because of hepatic (Kaufman et al., 1970) or renal failure. The lethal dose has been estimated to be between 0.5 and $1 \mathrm{~g}$ (Moeschlin, 1965).

There is enough evidence in the literature that potassium dichromate produces acute tubular necrosis by a direct toxic damage of tubular epithelium in man (Sander and Camp, 1939; Samitz, 1964) and in animals (Graham, 1962). Other factors such as acute gastro-intestinal fluid loss and hepatic necrosis, which are generally associated with this type of poisoning, may contribute to the development of renal failure. In the present case, haemolysis was evident by the rapid drop in haemoglobin level, raised free plasma haemoglobin and reticulocytosis. The case described by Fristedt et al. (1965) also developed anaemia, bilirubinaemia and reticulocytosis which were all attributed to the bleeding diathesis and hepatic necrosis. The possibility of intravascular haemolysis was not entertained. There is no mention of this association in the available literature. Potassium dichromate is a strong oxidant and this property may have contributed to the intravascular haemolysis in the present case. Intravascular haemolysis is well known as a cause of acute renal failure (Chugh et al., 1975). The authors consider this was an important contributory cause of the renal failure in this case.

It seems that the prognosis following potassium dichromate poisoning is always bad (Kaufman et al., 1970). Fristedt et al.'s (1965) patient recovered after dialysis. Haemodialysis (Fritz et al., 1960) and peritoneal dialysis (Kaufman et al., 1970) have been shown to be effective in removing potassium dichromate; but they are likely to be effective only if they are carried out very soon after the ingestion, when the blood levels are still high. In the present case, haemodialysis was carried out primarily for renal failure as the patient was not seen in this hospital until several days after ingestion of the potassium dichromate.

\section{References}

Chugh, K.S., Sharma, B.K., Yadav, R.V.S., Mahakur, A.C., Singhal, P.C., Dash, S.C. \& Dass, K.S. (1975) Acute renal failure due to intravascular haemolysis in the tropics. VI International Congress of Nephrology, Firenze. Abstract No. 567.

Fristedt, B., Lindevist, R., Schutz, A. \& Ovrum, P. (1965) Survival in a case of acute chromic acid poisoning with acute renal failure treated by haemodialysis. Acta medica scandinavica, 177, 153.

Fritz, K.W., Bohm, P. \& Lowen, C.H. (1960) Die akute gewerbliche dichromat Vergiftung und ihre Behandlung. Klinische Wochenschift, 38, 856.

Goldman, M. \& Karotkin, R. (1935) Acute potassium dichromate poisoning. American Journal of Medical Science, 189, 400.

Graham, J.D.P. (1962) The Diagnosis and Treatment of Acute Poisoning. Oxford University Press, London.

Kaufman, D.B., DiNicola, W. \& McIntosh, R. (1970) Acute potassium dichromate poisoning. American Journal of Diseases of Children, 119, 374.

Moeschlin, S. (1965) Poisoning: Diagnosis and Treatment, p. 145. New York, Grune \& Stratton Inc.

Pascalle, L.R., Waldstein, S.S., Engbring, G., Derbin, A. \& Szanto, P.B. (1952) Chromium intoxication with special reference to hepatic injury. Journal of the American Medical Association, 149, 1385.

SAmitz, M.H. (1964) A current review of the chromate problem. In: Dermatology Digest. Wirnetka, II Medical Digest, p. 69.

SANDAR, J.F. \& CAMP, C.O. (1939) Chromium poisoning in infancy. American Journal of Medical Science, 198, 551.

WALSH, E.N. (1953) Chromate hazards in industry. Journal of the American Medical Association, 153, 1305. 